\title{
Association of Antioxidative Enzymes Polymorphisms with Efficacy of Platin and Fluorouracil-Based Adjuvant Therapy in Gastric Cancer
}

\author{
Honghong Zhanga,b Weiyong Zhao ${ }^{a}$ Dongying $\mathrm{Gu}^{\mathrm{c}}$ Mulong $\mathrm{Du}^{\mathrm{d}}$ \\ Weida Gonge Yongfei Tan ${ }^{f}$ Meilin Wang ${ }^{d g}$ Juan Wen ${ }^{h}$ \\ Yongning Zhai ${ }^{\text {h }}$ Zhi Xua,c
}

\begin{abstract}
aDepartment of Oncology, Tongren Hospital, Shanghai Jiao Tong University School of Medicine, Shanghai, 'bepartment of Oncology, Taizhou People's Hospital, Taizhou, 'Department of Oncology, Nanjing First Hospital, Nanjing Medical University, Nanjing, dDepartment of Environmental Genomics, Jiangsu Key Laboratory of Cancer Biomarkers, Prevention and Treatment, Collaborative Innovation Center for Cancer Personalized Medicine, Nanjing Medical University, Nanjing, 'Department of Surgery, Yixing Cancer Hospital, Yixing, fDepartment of Surgery, Yixing People's Hospital, Yixing, '9Department of Genetic Toxicology, The Key Laboratory of Modern Toxicology of Ministry of Education, School of Public Health, Nanjing Medical University, Nanjing, hNanjing Maternity and Child Health Care Institute, The Affiliated Obstetrics and Gynecology Hospital of Nanjing Medical University (Nanjing Maternity and Child Health Care Hospital), Nanjing, China
\end{abstract}

\section{Key Words}

Gastric cancer • Adjuvant chemotherapy • Genetic polymorphism • Biomarker

\begin{abstract}
Background/Aims: Imbalance of oxidative/antioxidative enzymes in cells is associated with carcinogenesis and cancer cell chemoresistance. The aim of this study was to examine the clinical significance of potentially functional single nucleotides polymorphisms (SNPs) in antioxidative enzymes, GPxs and CAT, in stages II and III gastric cancer patients. Methods: A total of 591 gastric cancer patients who had radical gastrectomy were recruited. 207 patients received platinum and fluorouracil-based (PF-based) adjuvant chemotherapy and 384 patients were untreated. GPx1 rs1050450, GPx2 rs4902346, GPx3 rs736775, rs3828599 and CAT rs769218 were genotyped in the DNA samples extracted from paraffin-embedded tumor tissue. Results: CAT rs769218 was significantly correlated with the overall survival (OS) in the dominant model $(P=0.014)$. Multivariate analysis revealed that CAT rs $769218 \mathrm{GA} / \mathrm{AA}(\mathrm{HR}, 0.715 ; 95 \% \mathrm{CI}, 0.562-$ $0.910, P=0.006)$ was an independent prognostic marker indicating improved survival. After adjustments, GPx3 rs736775 TC/CC was significantly associated with improved OS (HR, 0.621;

H. Zhang, W. Zhao and D. Gu contributed equally to this work.

Zhi Xu

and Yongning Zhai

Dept. of Oncology, Tongren Hospital, Shanghai Jiao Tong University School of Medicine Shanghai;

Nanjing Maternity and Child Health Care Hospital, Nanjing (China)

E-Mail michelle.xuzhi@hotmail.com; yningny@sina.com
\end{abstract}


Zhang et al.: Associations of Antioxidative Genes' Snps in Gastric Cance

95\%CI, 0.399-0.965; $P=0.034)$ in patients treated with PF-based adjuvant chemotherapy, and CAT rs $769218 \mathrm{GA} / \mathrm{AA}$ was significantly associated with improved OS (HR, 0.646; 95\% CI, 0.482$0.864 ; P=0.003)$ in the untreated patients. PF-based chemotherapy significantly decreased risk of death for patients carrying GPX3 rs736775 TC/CC and age $\leq 60$ years or with diffused type adenocarcinoma compared to surgery alone. Conclusion: our findings suggested CAT rs769218 and GPX3 rs736775 may be considered as prognostic markers in gastric cancer. Patient stratification by GPX3 rs736775 and conventional pathological parameters may provide additional predictive information in treatment decision-making.

\section{Introduction}

Gastric cancer (GC) is the fourth most commonly diagnosed cancer worldwide and the second leading cause of cancer deaths in China [1-3]. Surgical resection is still the only curative treatment option for gastric cancer patients. Despite the implement of perioperative chemotherapy and chemoradiation therapy, the 5-year survival rate was only improved by 5-15\% [4-7]._ENREF_1_ENREF_1 Currently, platin and fluorouracilbased (PF-based) adjuvant chemotherapy is recommended by the main clinical practice guidelines as the standard of care for post-operative gastric cancer patients with stage II and III disease. Conventional clinicopathological parameters or comprehensive molecular classification using The Cancer Genome Atlas (TCGA) datasets only provide prognostic and tumor biological information [8], but not able to predict patients who would be benefit from adjuvant chemotherapy. Therefore, it is necessary to identify biomarkers that can be used to guide personalized therapy, exempting those patients from unnecessary potential exposure to toxicity and the financial burden of chemotherapy treatments.

The intrinsic regulation of reactive oxygen species (ROS) in cancer cells is one of the various molecular mechanisms involved in multidrug resistance and maintenance of cancer stemness $[9,10]$, which is considered as major causes of poor survival after multimodalities anti-cancer treatment. Increasing level of ROS has been observed in many cancer types and associated with activation of cancer initiation and progression related signaling, such as mitogen-activated protein (MAP) kinase/Erk [11], phosphoinositide-3-kinase (PI3K)/Akt [12] as well as the IкB kinase (IKK)/nuclear factor $\kappa-B$ (NF- $\kappa B$ ) pathways [13]. Chemotherapeutics such as platinum, taxane and fluorouracil may induce cancer cells death through inducing oxidative stress to highly toxic level. In the process of protecting cancer cells from oxidative damage, superoxide dismutases (SODs) convert superoxide radical into hydrogen peroxide, which is further detoxified into water by glutathione peroxidases (GPxs) and catalase (CAT). Cancer stem cells could survive through chemo drug-induced cells death and initiate recurrence by utilizing redox-regulatory mechanisms [14]. In response to chemotherapeutics and cytotoxic by-products, redox signaling pathways are frequently activated in cancer cells to acquire drug resistance $[15,16]$. In pancreatic cancer stem cells, chemoresistance to 5-fluorouracil and gemcitabine was related with suppressed ROS levels [17]. Active GPx1 was found in glioma stem cell lines, which mediated their resistant to oxidative stress induced cell death [18].

Genetic variations of antioxidant genes may alter their activity or function, contributing to the imbalance of ROS production and scavenging. GPx1 rs1050450 polymorphism causes a proline-leucine substitution at codon 198, which correlated with lipid peroxidation, GPx1 activity and breast cancer risk [19]. C-262T polymorphisms at CAT affected its expression in cells and serum level $[20,21]$. Previously, we reported SOD2 rs4880, which may regulate SOD2 catalyzation activity, could predict gastric patients' survival after receiving adjuvant chemotherapy [22]. However, the clinical significance of the genetic variations of the antioxidative enzymes regulating hydrogen peroxide scavenging has not been examined. Herein, we investigated the association of potentially functional single nucleotides polymorphisms (SNPs) in CAT, GPx1, GPx2 and GPx3 with adjuvant chemotherapy outcome in gastric cancer patients. 


\section{Cellular Physiology Cell Physiol Biochem 2018;48:2247-2257 \begin{tabular}{ll|l} 
and BiOChemistry & $\begin{array}{l}\text { DOI: 10.1159/000492642 } \\
\text { Published online: 15 August, } 2018\end{array}$ & $\begin{array}{l}\text { (c) } 2018 \text { The Author(s). Published by S. Karger AG, Basel } \\
\text { www.karger.com/cpb }\end{array}$ \\
\hline
\end{tabular}

\section{Materials and Methods}

\section{Patients}

All patients received curative surgery and diagnosed at stage II-III according to disease histological examinations and imaging studies by board-certified pathologists at the Yixing People's Hospital (Yixing, Jiangsu Province, China) between 1999 and 2006 were recruited for retrospective analysis [23]. None of them had perioperative chemoradiation or neoadjuvant chemotherapy. 207 patients had PF-based adjuvant chemotherapy within one month after surgery, and 384 patients received no adjuvant therapy for various reasons. Overall survival (OS) was determined from the date of surgery to the date of death or last follow-up (March 31, 2009, ranging from 3-118 months). The demographic features and clinicopathologic data are summarized in Table 1. Surgical specimens were processed immediately after the operation by fixing in buffered paraformaldehyde before embedding in paraffin. The samples used for genotyping were reviewed and classified by 2 independent pathologists. The study protocol was approved by the Institutional Review Board of Nanjing Medical University (Nanjing, China). All patients have given written informed consents on the use of clinical specimens for medical research.

\section{Treatment plan}

The adjuvant chemotherapy consisted of at least 4 cycles of PF-based regimens, including combinations of cisplatin and 5-fluorouracil, oxaliplatin and 5-fluorouracil. Chemotherapy was given only if the patient had neutrophil count of $\geq 1.5 \times 10^{9} / \mathrm{L}$, platelet count of $\geq 100 \times 10^{9} / \mathrm{L}$, hemoglobin level of $\geq 8 \mathrm{~g} / \mathrm{dl}$ and no sign of organ toxicity. Antiemetics and mannitol diuresis were given according to institutional protocols.

\section{SNP selection}

All common (minor allele frequency, MAF > 0.05 in the Han Chinese) polymorphisms in hydrogen peroxide scavenging related genes, $G P x$ and $C A T$, with potentially functional significance, that is, located at 5'-flanking regions (5'-FRs), 5'-untranslated regions (5'-UTRs), coding regions, or 3'-UTRs according to NCBI dbSNPs were identified. SNPs that were demonstrated to be of biological significance or associated with gene expression and/or cancer risk/survival according to the literature review were also included. If SNPs are in high linkage disequilibrium (LD) ( $\mathrm{r}^{2}>0.8$ ), only one SNP were genotyped. As a result, GPx1 rs1050450, GPx2 rs4902346, GPx3 rs736775, rs3828599 and CAT rs769218 were selected for genotyping and analysis (Table 2).

\section{Genotyping}

Genomic DNA was extracted from tumor specimens by proteinase K digestion, isopropanol extraction, and ethanol precipitation [24]. The SNPs were examined by multiplex TaqMan technology using ABI fluorescence-based allelic discrimination method (Applied Biosystems, Foster City, CA) as described previously [25]. The SNPs were analyzed using ABI 7900, and the genotypes were determined by using 


\section{Cellular Physiology Cell Physiol Biochem 2018;48:2247-2257 \begin{tabular}{ll|l} 
and Biochemistry Published onlıne: 15 August, 2018 & $\begin{array}{l}\text { (c) } 2018 \text { The Author(s). Published by S. Karger AG, Basel } \\
\text { www.karger.com/cpb }\end{array}$
\end{tabular}}

GeneMapper 4.0 software (Applied Biosystems). Genotyping was validated in randomly selected $10 \%$ of samples by Sanger sequencing, and the results were $100 \%$ concordant.

\section{Statistical analysis}

The SPSS Statistical Package for Windows (version 16; SPSS Inc. Chicago, IL) was used for data analysis. All statistical tests were two-sided, and an association was considered statistically significant with a $P$ value of $<0.05$. Kaplan-Meier survival curves and the log-rank test were used for survival analysis. Chi-squared test was used to assess differences in the frequencies of characteristics between patient sub-groups. Cox regression was used in the univariate survival analysis to determine the association of individual clinicopathologic variables with overall survival. All variables with $P<0.05$ in addition to age, sex and treatment arms were subsequently subjected to the multivariate Cox regression analysis in the corresponding cohort to determine the hazards ratios (HRs) and the independence of effects. Because of the exploratory nature of the study, all $P$ values were not adjusted for multiple comparisons [26].

\section{Results}

Patient Characteristics and Associations with the 5 SNPs

Among the 591 patients, GPx1 rs1050450, GPx2 rs4902346, GPx3 rs736775, rs3828599 and CAT rs769218 were successfully determined in more than $96 \%$ of the samples (Table 2 ). The associations between their genotypes and patient characteristics were examined. CAT rs769218 GA/GG were correlated with tumor at antrum $(P=0.003)$. GPX3 rs736775 TC/CC were associated with intestinal type of gastric adenocarcinoma $(P=0.036)$. In this population, 207 patients received PF-based adjuvant chemotherapy and 384 patients were untreated. As shown in the Table 1, patients over 60-year old tended to not have adjuvant chemotherapy $(P=0.002)$. The median age of patients treated with PF-based adjuvant chemotherapy was 59 years and that of untreated patients was 63 years. None of the rest clinicopathological parameters were found significantly different between the two cohorts. Excepted for GPx1 rs1050450 $(P=0.029)$, the allele distributions of the rest SNPs were consistent between different treatment groups.

\section{GPx3 rs736775 and CAT rs769218 as Prognostic Markers}

Univariate Cox regression was used to examine the associations between the 5 SNPs and OS in the total patients by using different genetic models (Table 2). $P$-values of Hardy-Weinberg equilibrium (HWE) were all greater than 0.05. None of GPxs related SNPs were found to have significant association with the OS. CAT rs769218 was significantly correlated with the OS in the dominant model $(P=0.014)$. Comparing to the patients carrying rs $769218 \mathrm{GG}$, those with GA/AA had a longer mean overall survival time (MST) of 69 months (Log-rank $=6.211$, $P=0.013)$. As for the conventional clinicopathological variables, lymph node metastasis $(P$ $=0.011)$ and tumor stage $(P<0.001)$ were significantly correlated with postoperative $0 S$ in the total patients. Multivariate analysis revealed that CAT rs769218 GA/AA (HR, 0.715; 95\%CI, $0.562-0.910, \quad P=$ 0.006) was an independent prognostic marker indicating improved survival beside advanced tumor stage (HR, 1.868; 95\%CI, 1.145-3.047; $P$ $=0.012$, Table 3).

The overall survival time did not show significant difference between patients treated with PF-based adjuvant chemotherapy and those untreated. Poor tumor

Table 2. Genotyping results with patients' survival ( $n=591)$. SNP, single nucleotide polymorphism; MAF, minor allele frequency; NA, not available. ${ }^{\mathrm{a}}$ major $>$ minor allele. ${ }^{\mathrm{b}} \mathrm{MAF}$ in Patients. ${ }^{\mathrm{c}}$ Calculated in univariate Cox regression. ${ }^{\mathrm{d}}$ only TT and CT genotypes were identified

\begin{tabular}{|c|c|c|c|c|c|c|c|}
\hline \multirow{2}{*}{ SNP } & \multirow{2}{*}{ Base change a } & \multirow{2}{*}{ Gene } & \multirow{2}{*}{ Location } & \multirow{2}{*}{ Genotyping Rate } & \multirow{2}{*}{ MAF b } & \multicolumn{2}{|c|}{$\mathrm{Pc}^{\mathrm{c}}$} \\
\hline & & & & & & Dominant model & Recessive model \\
\hline rs 1050450 & $\mathrm{~T}>\mathrm{C}$ & GPx1 & $3 \mathrm{p} 21.31$ & $98.1 \%$ & 0.057 & $0.149^{d}$ & NA \\
\hline rs4902346 & $\mathrm{C}>\mathrm{T}$ & GPx2 & $14 \mathrm{q} 23.3$ & $98.5 \%$ & 0.348 & 0.137 & 0.425 \\
\hline rs736775 & $\mathrm{T}>\mathrm{C}$ & GPx3 & $5 q 33.1$ & $96.8 \%$ & 0.341 & 0.608 & 0.742 \\
\hline rs3828599 & $\mathrm{T}>\mathrm{C}$ & GPx3 & $5 q 33.1$ & $96.4 \%$ & 0.480 & 0.944 & 0.177 \\
\hline rs769218 & $\mathrm{G}>\mathrm{A}$ & CAT & $11 \mathrm{p} 13$ & $99.0 \%$ & 0.445 & 0.014 & 0.244 \\
\hline
\end{tabular}


differentiation $(P=0.003)$, positive lymph node metastasis $(P=0.033)$, diffused type of tumor $(P=0.004)$ and advanced tumor stage $(P<0.001)$ were associated with shorter overall survival time in untreated cohort. In contrast, none of these clinicopathological parameters was found to significantly associate with OS in the treated patients. We further analyzed the 5 SNPs with overall survival in the two clinical settings (Table 4). When adjusted by age and sex, GPx3 rs736775 TC/CC was associated with improved OS (HR, 0.621; 95\%CI, 0.399-0.965; $P=0.034$ ) in patients treated with PF-based adjuvant chemotherapy. The MST was 48 months for patients carrying GPX3 rs736775 TT, compared to the MST of 69 months for those carrying TC/CC (Logrank $=4.641, P=0.031$, Fig. $1 \mathrm{~A}$ ). No such association was observed for the patients without adjuvant chemotherapy (Fig. 1B). The OS was not statistically different in treated patients with CAT rs769218 GG or GA/AA genotypes (Fig. 2A). However, in the untreated arm, CAT rs769218 GG was associated with shorter MST of 55 months than those carrying GA/AA (MST, 69

Table 3. Multivariable Cox regression analysis on patients' overall survival $(\mathrm{n}=591)$. HR, hazard ratio; $\mathrm{CI}$ : confident interval. Values in bold denote a significant $\mathrm{P}$ value $(\mathrm{P}<0.05)$. ${ }^{a}$ Data were defined according to the TNM classification (AJCC 7th, seven edition of the American Joint Commission on Cancer Staging Manual) for gastric cancer

\begin{tabular}{lcc}
\hline Variables & HR $(95 \% \mathrm{CI})$ & $\mathrm{P}$ \\
\hline $\begin{array}{l}\text { Age (years) } \\
\quad<=60\end{array}$ & 1 & 0.141 \\
$\quad>60$ & $1.196(0.942-1.518)$ & \\
Sex & 1 & 0.218 \\
$\quad$ Male & $1.189(0.903-1.565)$ & \\
$\quad$ Female & & 0.562 \\
Lymph node metastasis a & 1 & \\
$\quad$ N0 & $0.851(0.494-1.467)$ & \\
N1/N2/N3 & 1 & 0.012 \\
Tumor stage a & $1.868(1.145-3.047)$ & \\
$\quad$ II & & 0.006 \\
III & 1 & \\
CAT rs769218 & & \\
$\quad$ GG & & \\
$\quad$ GA/AA & &
\end{tabular}

Table 4. Association of 5 SNPs with gastric cancer patients' survival. HR, hazard ratio; CI, confidence intervals; Median, median overall survival time; Mean, mean overall survival time; NA, not available. ${ }^{a}$ Calculated in the multivariate Cox regression. ${ }^{\mathrm{b}}$ Mean overall survival time and median overall survival time were calculated in Kaplan-Meier analysis

\begin{tabular}{|c|c|c|c|c|c|c|c|c|c|}
\hline \multirow[b]{2}{*}{ Genetic models } & \multirow[b]{2}{*}{ Genotypes } & \multicolumn{4}{|c|}{ Treated $(n=207)$} & \multicolumn{4}{|c|}{ Untreated $(\mathrm{n}=384)$} \\
\hline & & $\begin{array}{c}\text { Mean } \\
\text { (months) }\end{array}$ & $\begin{array}{l}\text { Median } \\
\text { (months) }\end{array}$ & $\mathrm{Pa}$ & $\begin{array}{c}\mathrm{HR} \\
(95 \% \mathrm{CI})^{\text {a }}\end{array}$ & $\begin{array}{c}\text { Mean } \\
\text { (months) }\end{array}$ & $\begin{array}{c}\text { Median } \\
\text { (months) }\end{array}$ & $\mathrm{Pa}$ & $\operatorname{HR}(95 \% \mathrm{CI})$ a \\
\hline \multicolumn{10}{|l|}{ GPX1 rs1050450 T>C } \\
\hline & $\begin{array}{l}\text { TT } \\
\text { CT }\end{array}$ & $\begin{array}{l}63 \\
42\end{array}$ & $\begin{array}{l}\text { NA } \\
33\end{array}$ & 0.112 & $\begin{array}{c}1 \\
1.557(0.902-\end{array}$ & $\begin{array}{l}64 \\
55\end{array}$ & $\begin{array}{l}62 \\
38\end{array}$ & 0.259 & $\begin{array}{c}1 \\
1.302(0.824-2.059)\end{array}$ \\
\hline \multicolumn{10}{|l|}{ GPX2 rs4902346 C >T } \\
\hline \multirow[t]{3}{*}{ Codominant model } & CC & 53 & 62 & 0.380 & 1 & 60 & 43 & 0.147 & 1 \\
\hline & CT & 64 & NA & & $0.838(0.528-$ & 62 & 63 & & $0.803(0.594-1.086)$ \\
\hline & TT & 47 & 30 & & $1.342(0.673-$ & 73 & 88 & & $0.639(0.379-1.077)$ \\
\hline \multirow[t]{2}{*}{ Dominant model } & CC & 53 & 62 & 0.687 & 1 & 63 & 54 & 0.074 & 1 \\
\hline & $\mathrm{CT} / \mathrm{TT}$ & 62 & NA & & $0.914(0.590-$ & 65 & 65 & & $0.769(0.577-1.026)$ \\
\hline \multirow{2}{*}{ Recessive model } & $\mathrm{CT} / \mathrm{CC}$ & 62 & NA & 0.237 & 1 & 54 & 54 & 0.186 & 1 \\
\hline & TT & 47 & 30 & & $1.478(0.774-$ & 73 & 88 & & $0.713(0.431-1.177)$ \\
\hline \multirow{3}{*}{$\begin{array}{l}\text { GPX3 rs736775 } \mathrm{T}>\mathrm{C} \\
\text { Codominant model }\end{array}$} & TT & 48 & 42 & 0.091 & 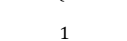 & & 63 & 0441 & 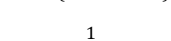 \\
\hline & TC & 70 & $\mathrm{NA}$ & & 0.757(0.370- & $\begin{array}{l}68 \\
58\end{array}$ & $\begin{array}{l}63 \\
58\end{array}$ & 0.441 & $\begin{array}{c}1 \\
1.295(0.833-2.014)\end{array}$ \\
\hline & $\mathrm{CC}$ & 46 & NA & & $0.583(0.359-$ & 60 & 50 & & $1.162(0.851-1.587)$ \\
\hline \multirow[t]{2}{*}{ Dominant model } & TT & 48 & 42 & 0.034 & 1 & 68 & 63 & 0.239 & 1 \\
\hline & $\mathrm{TC} / \mathrm{CC}$ & 69 & NA & & $0.621(0.399-$ & 60 & 54 & & $0.839(0.626-1.124)$ \\
\hline \multirow[t]{2}{*}{ Recessive model } & $\mathrm{TC} / \mathrm{TT}$ & 61 & $\mathrm{NA}$ & 0.875 & 1 & 65 & 62 & 0.382 & 1 \\
\hline & CC & 46 & NA & & $0.945(0.471-$ & 60 & 50 & & $0.832(0.552-1.256)$ \\
\hline \multicolumn{10}{|l|}{ GPX3 rs3828599 T >C } \\
\hline \multirow[t]{3}{*}{ Codominant model } & TT & 56 & 45 & 0.323 & 1 & 65 & 58 & 0.625 & 1 \\
\hline & $\mathrm{TC}$ & 64 & $\mathrm{NA}$ & & $0.952(0.524-$ & 60 & 63 & & $1.204(0.819-1.769)$ \\
\hline & $\mathrm{CC}$ & 50 & 62 & & $0.699(0.414-$ & 60 & 48 & & $1.059(0.751-1.493)$ \\
\hline \multirow[t]{2}{*}{ Dominant model } & TT & 57 & 45 & 0.303 & 1 & 62 & 56 & 0.518 & 1 \\
\hline & $\mathrm{TC} / \mathrm{CC}$ & 61 & NA & & $0.773(0.474-$ & 65 & 58 & & $1.110(0.809-1.523)$ \\
\hline \multirow[t]{2}{*}{ Recessive model } & TC/TT & 63 & NA & 0.457 & 1 & 60 & 48 & 0.361 & 1 \\
\hline & CC & 50 & 62 & & 1.208 & 63 & 63 & & $0.859(0.620-1.190)$ \\
\hline \multirow{4}{*}{$\begin{array}{l}\text { CAT rs769218 G>A } \\
\text { Codominant model }\end{array}$} & & & & & & & & & \\
\hline & GG & 50 & 51 & 0.339 & 1 & 55 & 37 & 0.006 & 1 \\
\hline & GA & 66 & NA & & $0.705(0.436-$ & 74 & 94 & & $0.586(0.422-0.816)$ \\
\hline & $\mathrm{AA}$ & 44 & NA & & $0.926(0.516-$ & 58 & 47 & & $0.754(0.523-1.087)$ \\
\hline \multirow[t]{2}{*}{ Dominant model } & $\mathrm{GG}$ & 51 & 51 & 0.234 & 1 & 55 & 37 & 0.003 & 1 \\
\hline & GA/AA & 64 & NA & & $0.767(0.495-$ & 69 & 77 & & $0.646(0.482-0.864)$ \\
\hline \multirow{2}{*}{ Recessive model } & $\mathrm{GA} / \mathrm{GG}$ & 62 & NA & 0.681 & 1 & 66 & 62 & 0.980 & \\
\hline & AA & 44 & $\mathrm{NA}$ & & $1.118(0.656-$ & 58 & 47 & & $1.004(0.721-1.398)$ \\
\hline \multicolumn{10}{|c|}{ Combined effects of GPX3 rs736775-C and CAT rs769218-A } \\
\hline & 0 & 43 & 31 & 0.076 & 1 & 56 & 35 & 0.548 & 1 \\
\hline & $1-2$ & 64 & NA & & $0.590(0.357-$ & 65 & 63 & & $0.840(0.526-1.339)$ \\
\hline & 3-4 & 44 & NA & & $0.503(0.231-$ & 64 & 62 & & $0.746(0.423-1.316)$ \\
\hline
\end{tabular}


months; Log-rank $=5.355, P=0.021$, Fig. 2B). The significant difference remained (CAT rs769218 GA/AA, HR, 0.646; $95 \%$ CI, 0.482-0.864; $P=$ 0.003 ) after adjustment for age, sex, tumor differentiation, lymph node metastasis, Lauren classification and tumor stage (stage III, HR, 2.100; 95\% CI, 1.172-3.764; $P=0.013$ ). Then, we evaluated the combined effects on overall survival in the two clinical settings by adding the number of variant alleles of the two significant SNPs (GPX3 rs736775-C and CAT rs769218-A). The "0" allele means subjects with wide-type homozygotes of the two SNPs; "1-4" alleles means carrying one to four variant alleles of the two SNPs. When compared with the subjects with wide-type homozygotes of the two SNPs, subjects carrying "1-2" variant alleles had an improved survival (HR, 0.590; 95\%CI, 0.357-0.973; $P=0.039$ ).

\section{GPx3 rs736775 Polymorphisms as} a Predictive Marker

When the patients were divided by the genetic models, none of GPx1 rs1050450, GPx2 rs4902346, GPX3 rs3828599 or CAT rs769218 genotypes associated with survival benefit from adjuvant chemotherapy (all $P>0.05$ ). Initial analysis showed the treatment benefit was present in patients with GPx3 rs736775 TC/CC but not in those with TT genotype (Fig. $3 \mathrm{~A}$ and $3 \mathrm{~B}$ ). The MST was 69 months for the patients treated with PFbased adjuvant chemotherapy, which is significantly longer than the MST (60 months) of untreated patients (Log-rank $=3.953, P=0.047)$. For the patients carrying GPx3 rs736775 TC/CC, lymph node metastasis $(P=$ $0.008)$ and tumor stage $(P=0.001)$ were significantly associated with OS in univariate analysis. When adjusted by age, sex and these cofounders, adjuvant chemotherapy showed a trend towards lower risk of death than untreated patients with GPx3 rs736775 TC/CC (HR, 0.698; 95\% CI, 0.471-1.034; $P=0.073$ ). We further performed stratification analysis. No treatment benefit was observed in patients with GPx3 rs736775 TC/CC of stage II (HR, $0.724 ; 95 \% \mathrm{CI}, 0.310-1.694 ; P=0.457$ ) or stage III disease (HR, 0.708; 95\% CI, 0.453-1.108; $P=0.131$ ). PF-based chemotherapy significantly decreased risk of death for patients carrying GPx3 rs736775 TC/CC and age $\leq 60$ years (HR, 0.542 ; 95\% CI, 0.303-0.970; $P=0.039$; Fig. 4A) or with diffused type adenocarcinoma (HR,

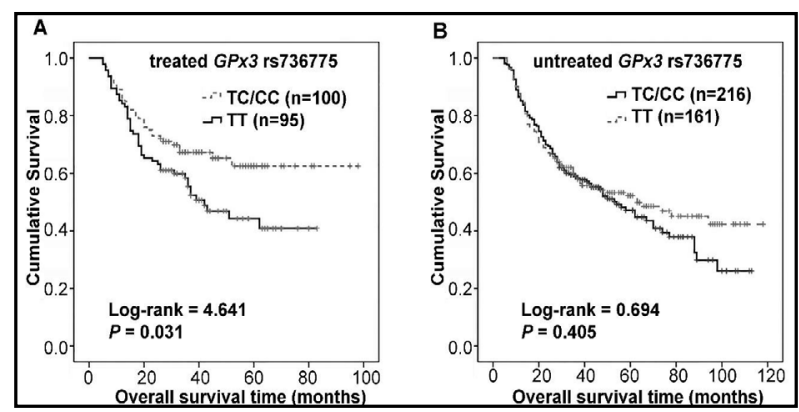

Fig. 1. Kaplan-Meier analyses of OS of treated/untreated patients by GPx3 rs736775 genotypes. (A) OS of treated patients by GPx3 rs736775 genotypes. (B) OS of untreated patients by GPx3 rs736775 genotypes.

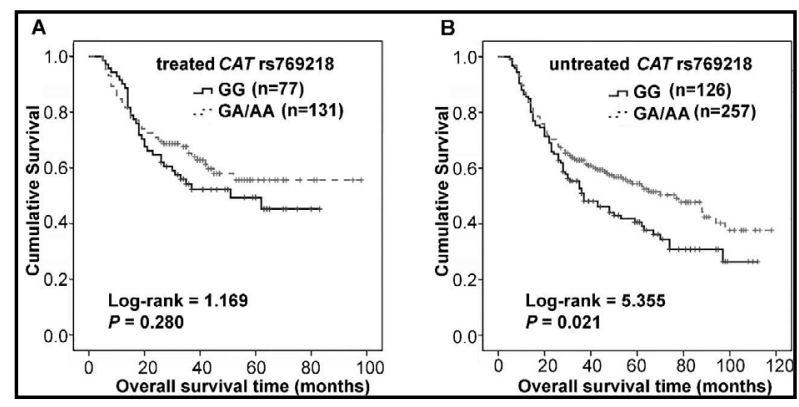

Fig. 2. Kaplan-Meier analyses of OS of treated/untreated patients by CAT rs769218 genotypes. (A) OS of treated patients by CAT rs769218 genotypes. (B) OS of untreated patients by CAT rs769218 genotypes.

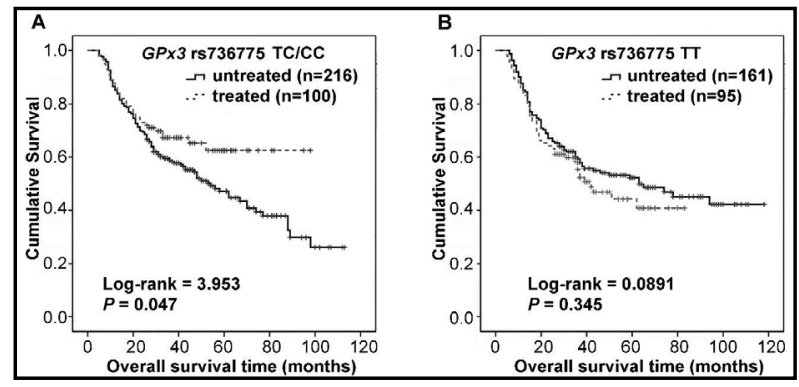

Fig. 3. Kaplan-Meier analyses of OS of patients carrying GPX3 rs736775 TC/CC or TT by treatment status. (A) OS of patients with GPx3 rs736775 TC/CC by treatment status. (B) OS of patients with GPx3 rs736775 TT by treatment status. 
$0.506 ; 95 \% \mathrm{CI}, 0.308$ to $0.831 ; P=$ 0.007; Fig. 4C) compared to surgery alone. As for patients carrying GPX3 rs736775 TT, no protective effect from adjuvant chemotherapy was observed in those at younger age or with the diffused type of tumor (Fig. $4 B$ and 4D).

\section{Discussion}

Adjuvant PF-based therapy in patients with locally advanced (stage II or III) gastric adenocarcinoma is well accepted worldwide. Both CLASSIC (Capecitabine and Oxaliplatin Adjuvant Study in Stomach Cancer) and ACTS-GC (Adjuvant Chemotherapy Trial of TS-1 for Gastric Cancer) studies demonstrated a significant increase of 5-year overall survival rate by only $10-15 \%$ given the adjuvant chemotherapy $[27,28]$. The modest clinical benefit of PF-based adjuvant chemotherapy in gastric cancer patients underlines the need for prognostic and predictive markers to optimize the surveillance and treatment strategy.

In the present study, the clinical associations of 5 SNPs of 4 redox related genes, CAT and GPX1-3, were explored in stage II-III postoperative gastric cancer patients. CAT rs769218 was a significant prognostic marker independent of age, sex, lymph node involvement, tumor differentiation, Lauren classification and tumor stage in postoperative patients. Further stratification analysis revealed the protective effect of rs769218 GA/GG on overall survival was observed in patients without adjuvant chemotherapy. On the other hand, GPx3 rs736775 TC/CC was associated with improved overall survival in patients received PF-based adjuvant chemotherapy. Both of their prognostic effects maintained in multivariate models.

Regarding as predictive markers, none of the 5 SNPs was demonstrated of significant association with treatment benefit in multivariate models. Although PF-based adjuvant chemotherapy showed a trend towards lower risk of death for patients with GPx3 rs736775 TC/CC (adjusted HR, 0.68; $P=0.053$ ), our data do not support $G P x 3 \mathrm{rs} 736775 \mathrm{TC} / \mathrm{CC}$ as a sole biomarker to recommend PF-based adjuvant treatment for patients with either stage II or III disease. For patients with GPx3 rs736775 TC /CC, age ( $\leq 60$ years) and tumor differentiation (diffused type) should be taken into consideration to recommend this regimen.

Patients after radical surgery and adjuvant therapy, cancer progression often occur and be subject to local recurrence and distant metastasis, which are partially related with chemoresistance and cancer stem cell persistence. Fluorouracil and platin are commonly used in adjuvant chemotherapy, which may be able to eliminate micrometastasis lesion through increasing intracellular ROS level and subsequently inducing cell death $[17,29]$. Increased ROS have shown both pros and cons in cancer initiation and progression [30]. High level of ROS was found in tumor cells than adjacent nontumor counterparts, which cause damage to nucleic acids and lead to mutation, genomic instability and carcinogenesis. However, reducing ROS level through antioxidants accelerated tumor development and metastatic potential in lung [31], melanoma [32,33] and breast cancer cells [34]. Activation 


\section{Cellular Physiology Cell Physiol Biochem 2018;48:2247-2257 \begin{tabular}{l|l} 
DOI: 10.1159/000492642 & $\begin{array}{l}\text { O 2018 The Author(s). Published by S. Karger AG, Basel } \\
\text { www.karger.com/cpb }\end{array}$ \\
\hline
\end{tabular}}

of redox signaling or its related elements have been found to associate with maintaining low intracellular ROS level and contribute to cancer stem cell survive and chemoresistance [35, 36].

CAT and GPxs are major cellular antioxidants reducing oxygen free radicals like $\mathrm{H}_{2} \mathrm{O}_{2}$. CAT expression was reported to increase [37] or decrease [38] in gastric carcinoma compared to non-tumor tissue. Under-expression of CAT in cancer cells related with chemoresistance to doxorubicin [39]. Retaining CAT activity showed enhancing cisplatin toxicity in breast cancer mouse models [40]. Genetic variation in CAT have been found to associate with impaired CAT activity and certain diseases [41]. Two common CAT SNPs, rs1001179 and rs794316, were found to be associated with prostate cancer risk and survival $[42,43]$. So far, there is no riskrelated CAT polymorphisms identified in gastric cancer [44, 45]. Rs769218, an intronic SNP in $C A T$, was found associated with breast overall survival in patients who did not received radiotherapy [46]. In our study, CAT rs769218 GG was associated with poor overall survival compared to GA/AA genotypes in patients without PF-based adjuvant chemotherapy. These results suggest CAT rs769218 may have potential effect modified by treatment and further functional studies are needed.

GPx3 was found frequently down-regulated in cancer tissues including breast, lung and gastric cancer [47], which may due to its promoter hypermethylation [48-50]. Silencing or decreased activity of GPX3 is correlated with increased ROS level and contributes to cancer initiation [51] and metastasis [52,53]. Reduced expression of GPx3 could enhance platin sensitivity in colorectal cancer [54], and increased expression was related with low intracellular ROS level and maintaining cancer stem cell phenotype in leukemia stem cells [36]. Two intronic polymorphisms of GPx3, rs3805435 and rs3828599, were shown to influence gene expression and correlate with gastric cancer risk [55]. GPx3 rs736775 C allele was found indicating better survival in colorectal cancer [56]. In our study, the protective effect of GPx3 rs736775 C allele was demonstrated in patients treated with PF-based adjuvant therapy. Whether this polymorphism has an effect on its expression needs further investigation.

Although our study showed the presence of CAT rs769218 GA/AA or GPx3 rs736775 TC/ CC were important prognostic and/or predictive markers for certain gastric cancer patients, there are several cautions should be noted. Patients in this analysis were from a Chinese retrospective cohort and allele's distribution could be different worldwide. The clinical significance of CAT rs769218 and GPX3 rs736775 in gastric cancer should be verified in other populations and patients from randomized clinical trials. Second, there is no consensus on adjuvant chemo regimen for gastric cancer. Taxane, platin and fluorouracil-based drugs such as capecitabine and S-1, were often used in different combinations. Our data only showed patients with GPX3 rs736775 TC/CC could be benefit from PF-based chemotherapy, thus, it may not be appropriate for guiding adjuvant chemotherapy if other regimens were employed. Third, the biological functions of these genetic variations were not investigated or reported in the literature. Future studies that examining those variants related gene transcription and function would be useful for improve adjuvant chemotherapy efficacy.

In conclusion, CAT rs $769218 \mathrm{GA} / \mathrm{AA}$ and $G P x 3 \mathrm{rs} 736775 \mathrm{TC} / \mathrm{CC}$ could serve as prognostic markers for postoperative gastric cancer patients. Moreover, $G P x 3$ rs736775 genetic models showed specific influences on PF-based adjuvant chemotherapy outcome in some subtypes of gastric cancer. These results suggested that combined with pathological parameters and GPx3 rs736775 genotypes could help clinical decision-making. Future prospective clinical trials to validate these findings and design for effective regimens for personalized therapy are needed.

\section{Acknowledgements}

We thank Dr. John M Luk (Department of Translational and Clinical Medicine, Arbele Limited, Hong Kong Science Park, Shatin, N.T. Hong Kong) for critical reading of the article. 


\section{Cellular Physiology Cell Physiol Biochem 2018;48:2247-2257 \begin{tabular}{l|l|l} 
DOI: 10.1159/000492642 & $\begin{array}{l}\text { O 2018 The Author(s). Published by S. Karger AG, Basel } \\
\text { www.karger.com/cpb }\end{array}$
\end{tabular}}

This work was supported by the Nanjing Medical Science and Technique Development Foundation (QRX17061) to Zhi Xu, the National Natural Science Foundation of China (81600685) and the Natural Science Foundation of Jiangsu Province (BK20160141) to Juan Wen. Z.X and Y.Z designed the study. W.Z, H.Z, D.G, M.D, W.G, Y.T and M.W collected the data. J.W, Z.X and Y.Z conducted the statistical analysis and interpretation. W.Z, H.Z and D.G wrote the report. J.W and Z.X revised the report. All the authors reviewed the report and approved the final version.

\section{Disclosure Statement}

There are no relevant conflicts of interest to disclose.

\section{References}

1 Chen W, Zheng R, Baade PD, Zhang S, Zeng H, Bray F, Jemal A, Yu XQ He J: Cancer statistics in China, 2015. CA Cancer J Clin 2016;66:115-132.

2 Van Cutsem E, Sagaert X, Topal B, Haustermans K, Prenen H: Gastric cancer. Lancet 2016;388:2654-2664.

3 Siegel RL, Miller KD, Jemal A: Cancer Statistics, 2017. CA Cancer J Clin 2017;67:7-30.

-4 GASTRIC (Global Advanced/Adjuvant Stomach Tumor Research International Collaboration) Group, Paoletti X, Oba K, Burzykowski T, Michiels S, Ohashi Y, Pignon JP, Rougier P, Sakamoto J, Sargent D, Sasako M, Van Cutsem E, Buyse M: Benefit of adjuvant chemotherapy for resectable gastric cancer: a meta-analysis. JAMA 2010;303:1729-1737.

-5 Jiang L, Yang KH, Guan QL, Chen Y, Zhao P, Tian JH: Survival benefit of neoadjuvant chemotherapy for resectable cancer of the gastric and gastroesophageal junction: a meta-analysis. J Clin Gastroenterol 2015;49:387-394.

-6 Brower V: Apatinib in treatment of refractory gastric cancer. Lancet Oncol 2016;17:e137.

7 Kumagai K, Rouvelas I, Tsai JA, Mariosa D, Lind PA, Lindblad M, Ye W, Lundell L, Schuhmacher C, Mauer M, Burmeister BH, Thomas JM, Stahl M, Nilsson M: Survival benefit and additional value of preoperative chemoradiotherapy in resectable gastric and gastro-oesophageal junction cancer: a direct and adjusted indirect comparison meta-analysis. Eur J Surg Oncol 2015;41:282-294.

8 Cancer Genome Atlas Research N: Comprehensive molecular characterization of gastric adenocarcinoma. Nature 2014;513:202-209.

9 Galadari S, Rahman A, Pallichankandy S, Thayyullathil F: Reactive oxygen species and cancer paradox: To promote or to suppress? Free Radic Biol Med 2017;104:144-164.

10 Kuo MT: Redox regulation of multidrug resistance in cancer chemotherapy: molecular mechanisms and therapeutic opportunities. Antioxid Redox Signal 2009;11:99-133.

11 Chan DW, Liu VW, Tsao GS, Yao KM, Furukawa T, Chan KK, Ngan HY: Loss of MKP3 mediated by oxidative stress enhances tumorigenicity and chemoresistance of ovarian cancer cells. Carcinogenesis 2008;29:1742-1750.

12 Liu LZ, Hu XW, Xia C, He J, Zhou Q Shi X, Fang J, Jiang BH: Reactive oxygen species regulate epidermal growth factor-induced vascular endothelial growth factor and hypoxia-inducible factor-1alpha expression through activation of AKT and P70S6K1 in human ovarian cancer cells. Free Radic Biol Med 2006;41:15211533.

13 Marinho HS, Real C, Cyrne L, Soares H, Antunes F: Hydrogen peroxide sensing, signaling and regulation of transcription factors. Redox Biol 2014;2:535-562.

14 Ding S, Li C, Cheng N, Cui X, Xu X, Zhou G: Redox Regulation in Cancer Stem Cells. Oxid Med Cell Longev 2015;2015:750798.

15 Cort A, Ozben T, Saso L, De Luca C, Korkina L: Redox Control of Multidrug Resistance and Its Possible Modulation by Antioxidants. Oxid Med Cell Longev 2016;2016:4251912.

16 Landriscina M, Maddalena F, Laudiero G, Esposito F: Adaptation to oxidative stress, chemoresistance, and cell survival. Antioxid Redox Signal 2009;11:2701-2716. 


\section{Cellular Physiology Cell Physiol Biochem 2018;48:2247-2257 \begin{tabular}{l|l|l} 
DOI: 10.1159/000492642 & $\begin{array}{l}\text { O 2018 The Author(s). Published by S. Karger AG, Basel } \\
\text { www.karger.com/cpb }\end{array}$
\end{tabular}}

17 Suzuki S, Okada M, Shibuya K, Seino M, Sato A, Takeda H, Seino S, Yoshioka T, Kitanaka C: JNK suppression of chemotherapeutic agents-induced ROS confers chemoresistance on pancreatic cancer stem cells. Oncotarget 2015;6:458-470.

18 Dokic I, Hartmann C, Herold-Mende C, Regnier-Vigouroux A: Glutathione peroxidase 1 activity dictates the sensitivity of glioblastoma cells to oxidative stress. Glia 2012;60:1785-1800.

19 Jablonska E, Gromadzinska J, Peplonska B, Fendler W, Reszka E, Krol MB, Wieczorek E, Bukowska A, Gresner P, Galicki M, Zambrano Quispe O, Morawiec Z, Wasowicz W: Lipid peroxidation and glutathione peroxidase activity relationship in breast cancer depends on functional polymorphism of GPX1. BMC Cancer 2015;15:657.

20 Saify K, Saadat I, Saadat M: Influence of A-21T and C-262T genetic polymorphisms at the promoter region of the catalase (CAT) on gene expression. Environ Health Prev Med 2016;21:382-386.

-21 Forsberg L, Lyrenas L, de Faire U, Morgenstern R: A common functional C-T substitution polymorphism in the promoter region of the human catalase gene influences transcription factor binding, reporter gene transcription and is correlated to blood catalase levels. Free Radic Biol Med 2001;30:500-505.

-22 Xu Z, Chen Y, Gu D, Lee NP, Sun S, Gong W, Tan Y, Luk JM, Chen J: SOD2 rs4880 CT/CC genotype predicts poor survival for Chinese gastric cancer patients received platinum and fluorouracil based adjuvant chemotherapy. Am J Transl Res 2015;7:401-410.

23 Xu Z, Zhu H, Luk JM, Wu D, Gu D, Gong W, Tan Y, Zhou J, Tang J, Zhang Z, Wang M, Chen J: Clinical significance of SOD2 and GSTP1 gene polymorphisms in Chinese patients with gastric cancer. Cancer 2012;118:54895496.

24 Wang M, Bai J, Tan Y, Wang S, Tian Y, Gong W, Zhou Y, Gao Y, Zhou J, Zhang Z: Genetic variant in PSCA predicts survival of diffuse-type gastric cancer in a Chinese population. Int J Cancer 2011;129:1207-1213.

-25 Xiao HW, Lai XY, Luo Y, Shi JM, Tan YM, He JS, Xie WZ, Li L, Zhu XL, Zhu JJ, Sun J, Wei GQ Jin L, Liu LZ, Wu KN, Yu XH, Cai Z, Lin MF, Ye XJ, Huang H: Relationship between TNFA, TNFB and TNFRII gene polymorphisms and outcome after unrelated hematopoietic cell transplantation in a Chinese population. Bone Marrow Transplant 2011;46:400-407.

-26 Xu MZ, Yao TJ, Lee NP, Ng IO, Chan YT, Zender L, Lowe SW, Poon RT, Luk JM: Yes-associated protein is an independent prognostic marker in hepatocellular carcinoma. Cancer 2009;115:4576-4585.

27 Noh SH, Park SR, Yang HK, Chung HC, Chung IJ, Kim SW, Kim HH, Choi JH, Kim HK, Yu W, Lee JI, Shin DB, Ji J, Chen JS, Lim Y, Ha S, Bang YJ, CLASSIC trial investigators: Adjuvant capecitabine plus oxaliplatin for gastric cancer after D2 gastrectomy (CLASSIC): 5-year follow-up of an open-label, randomised phase 3 trial. Lancet Oncol 2014;15:1389-1396.

28 Sasako M, Sakuramoto S, Katai H, Kinoshita T, Furukawa H, Yamaguchi T, Nashimoto A, Fujii M, Nakajima T, Ohashi Y: Five-year outcomes of a randomized phase III trial comparing adjuvant chemotherapy with S-1 versus surgery alone in stage II or III gastric cancer. J Clin Oncol 2011;29:4387-4393.

-29 Tsai SY, Sun NK, Lu HP, Cheng ML, Chao CC: Involvement of reactive oxygen species in multidrug resistance of a vincristine-selected lymphoblastoma. Cancer Sci 2007;98:1206-1214.

-30 Chio IIC, Tuveson DA: ROS in Cancer: The Burning Question. Trends Mol Med 2017;23:411-429.

-31 Sayin VI, Ibrahim MX, Larsson E, Nilsson JA, Lindahl P, Bergo MO: Antioxidants accelerate lung cancer progression in mice. Sci Transl Med 2014;6:221ra215.

32 Le Gal K, Ibrahim MX, Wiel C, Sayin VI, Akula MK, Karlsson C, Dalin MG, Akyurek LM, Lindahl P, Nilsson J, Bergo MO: Antioxidants can increase melanoma metastasis in mice. Sci Transl Med 2015;7:308re308.

-33 Piskounova E, Agathocleous M, Murphy MM, Hu Z, Huddlestun SE, Zhao Z, Leitch AM, Johnson TM, DeBerardinis RJ, Morrison SJ: Oxidative stress inhibits distant metastasis by human melanoma cells. Nature 2015;527:186-191.

34 Deghan Manshadi S, Ishiguro L, Sohn KJ, Medline A, Renlund R, Croxford R, Kim YI: Folic acid supplementation promotes mammary tumor progression in a rat model. PLoS One 2014;9:e84635.

35 Wu T, Harder BG, Wong PK, Lang JE, Zhang DD: Oxidative stress, mammospheres and Nrf2-new implication for breast cancer therapy? Mol Carcinog 2015;54:1494-1502.

-36 Herault O, Hope KJ, Deneault E, Mayotte N, Chagraoui J, Wilhelm BT, Cellot S, Sauvageau M, AndradeNavarro MA, Hebert J, Sauvageau G: A role for GPx3 in activity of normal and leukemia stem cells. J Exp Med 2012;209:895-901. 


\section{Cellular Physiology Cell Physiol Biochem 2018;48:2247-2257 \begin{tabular}{ll|l} 
DOI: 10.1159/000492642 & $\begin{array}{l}\text { O 2018 The Author(s). Published by S. Karger AG, Basel } \\
\text { www.karger.com/cpb }\end{array}$
\end{tabular}}

-37 Hwang TS, Choi HK, Han HS: Differential expression of manganese superoxide dismutase, copper/zinc superoxide dismutase, and catalase in gastric adenocarcinoma and normal gastric mucosa. Eur J Surg Oncol 2007;33:474-479.

-38 Monari M, Foschi J, Calabrese C, Liguori G, Di Febo G, Rizzello F, Gionchetti P, Trinchero A, Serrazanetti GP: Implications of antioxidant enzymes in human gastric neoplasms. Int J Mol Med 2009;24:693-700.

-39 Kim HS, Lee TB, Choi CH: Down-regulation of catalase gene expression in the doxorubicin-resistant AML subline AML-2/DX100. Biochem Biophys Res Commun 2001;281:109-114.

-40 Zhang R, Song X, Liang C, Yi X, Song G, Chao Y, Yang Y, Yang K, Feng L, Liu Z: Catalase-loaded cisplatinprodrug-constructed liposomes to overcome tumor hypoxia for enhanced chemo-radiotherapy of cancer. Biomaterials 2017;138:13-21.

41 Goth L, Rass P, Pay A: Catalase enzyme mutations and their association with diseases. Mol Diagn 2004;8:141-149.

42 Liu K, Liu X, Wang M, Wang X, Kang H, Lin S, Yang P, Dai C, Xu P, Li S, Dai Z: Two common functional catalase gene polymorphisms (rs1001179 and rs794316) and cancer susceptibility: evidence from 14, 942 cancer cases and 43, 285 controls. Oncotarget 2016;7:62954-62965.

43 Wang CD, Sun Y, Chen N, Huang L, Huang JW, Zhu M, Wang T, Ji YL: The Role of Catalase C262T Gene Polymorphism in the Susceptibility and Survival of Cancers. Sci Rep 2016;6:26973.

-44 Lee JH, Park RY, Lee CS, Jeoung EJ, Nam SY, Lee JG, Han KY, Lee HJ, Chung JH, Ahn YG, Yim SV, Cho JY, Park YH: No Association between Catalase Gene Polymorphism and Gastric Carcinoma and Hepatocellular Carcinoma in Koreans. Cancer Res Treat 2002;34:432-435.

45 Ebrahimpour S, Saadat I: Association of CAT C-262T and SOD1 A251G single nucleotide polymorphisms susceptible to gastric cancer. Mol Biol Res Commun 2014;3:223-229.

46 Seibold P, Hall P, Schoof N, Nevanlinna H, Heikkinen T, Benner A, Liu J, Schmezer P, Popanda O, FleschJanys D, Chang-Claude J: Polymorphisms in oxidative stress-related genes and mortality in breast cancer patients--potential differential effects by radiotherapy? Breast 2013;22:817-823.

47 Brigelius-Flohe R, Maiorino M: Glutathione peroxidases. Biochim Biophys Acta 2013;1830:3289-3303.

48 Mohamed MM, Sabet S, Peng DF, Nouh MA, El-Shinawi M, El-Rifai W: Promoter hypermethylation and suppression of glutathione peroxidase 3 are associated with inflammatory breast carcinogenesis. Oxid Med Cell Longev 2014;2014:787195.

49 Peng DF, Hu TL, Schneider BG, Chen Z, Xu ZK, El-Rifai W: Silencing of glutathione peroxidase 3 through DNA hypermethylation is associated with lymph node metastasis in gastric carcinomas. PLoS One 2012;7:e46214.

50 An BC, Jung NK, Park CY, Oh IJ, Choi YD, Park JI, Lee SW: Epigenetic and Glucocorticoid Receptor-Mediated Regulation of Glutathione Peroxidase 3 in Lung Cancer Cells. Mol Cells 2016;39:631-638.

51 Chang SN, Lee JM, Oh H, Park JH: Glutathione Peroxidase 3 Inhibits Prostate Tumorigenesis in TRAMP Mice. Prostate 2016;76:1387-1398.

52 Zhao H, Li J, Li X, Han C, Zhang Y, Zheng L, Guo M: Silencing GPX3 Expression Promotes Tumor Metastasis in Human Thyroid Cancer. Curr Protein Pept Sci 2015;16:316-321.

53 Yu YP, Yu G, Tseng G, Cieply K, Nelson J, Defrances M, Zarnegar R, Michalopoulos G, Luo JH: Glutathione peroxidase 3, deleted or methylated in prostate cancer, suppresses prostate cancer growth and metastasis. Cancer Res 2007;67:8043-8050.

54 Pelosof L, Yerram S, Armstrong T, Chu N, Danilova L, Yanagisawa B, Hidalgo M, Azad N, Herman JG: GPX3 promoter methylation predicts platinum sensitivity in colorectal cancer. Epigenetics 2017;12:540-550.

55 Wang JY, Yang IP, Wu DC, Huang SW, Wu JY, Juo SH: Functional glutathione peroxidase 3 polymorphisms associated with increased risk of Taiwanese patients with gastric cancer. Clin Chim Acta 2010;411:14321436.

56 Noci S, Dugo M, Bertola F, Melotti F, Vannelli A, Dragani TA, Galvan A: A subset of genetic susceptibility variants for colorectal cancer also has prognostic value. Pharmacogenomics J 2016;16:173-179. 